\title{
Rat intestinal mucosal responses to a microbial flora and different diets
}

\author{
R Sharma, U Schumacher, V Ronaasen, M Coates
}

\begin{abstract}
The effects of diet on the histochemical composition of intestinal mucosubstances and the morphology of the villi and crypts were investigated by comparing the data of germ free and conventionally maintained rats fed either a purified diet or a commercial diet. The influence of intestinal microflora was evaluated by comparing the germ free rats and those harbouring either a conventional rat flora or a human microbial flora. In both germ free rats and those maintained conventionally, feeding a purified diet resulted in shallower crypts in the small intestine but deeper crypts in the large intestine compared with their counterparts fed on the commercial diet. The preliminary data obtained with association of human flora showed a reduction of the villus height and crypt depth in the small intestine and, to some extent, the amount of neutral mucins in the goblet cells of both small and large intestine and an increase in the amount of sulphated mucins in the large intestine. In rats given the commercial diet the periodic acid Schiff staining for neutral mucins was more intense in the upper crypts of the small intestine than in the lower crypts, and to a lesser extent in the upper crypts of the large intestine. These results provide evidence that the dietary composition, microbial flora, as well as the interactions between the dietary constituents and microbial flora change the mucosal architecture and the mucus composition and therefore alter the functional characteristics of the intestinal tract.
\end{abstract}

(Gut 1995; 36: 209-214)

Keywords: diet, microbial flora, intestinal mucosa.

A distinguishing feature of the gastrointestinal Human Morphology, University of Southampton R Sharma

U Schumacher

School of Biological Sciences, University of Surrey, Guildford, Surrey

V Ronaasen

M Coates

Correspondence to: Mr R Sharma, Human Morphology, University of Crescent East, Southampton.

Accepted for publication 29 April 1994 special interest because changes in dietary habits may modify their chemical composition. ${ }^{3}$ Since dietary factors that either affect the production of mucin or enhance its degradation would make the intestinal mucosa vulnerable to toxic substances, it is possible that appropriate modifications of the diet may protect the intestinal mucosa from various diseases.

Studies in various animal models, as well as in humans, have shown that many bacterial species colonise the gastrointestinal tract by attachment to the mucus layer, ${ }^{45}$ and degrade mucin glycoproteins in vivo 6 and in vitro. ${ }^{7}$ Little is known, however, about the influence the gut microbial flora may exert on the secretory pattern of the intestinal mucins.

The histochemical characterisation of intestinal mucins in laboratory animals and in humans has received growing attention (for review, see: $\operatorname{rat}^{8}{ }^{9}$; human ${ }^{10}$ ) and different chemical compositions of these mucins have been observed in different parts of the gastrointestinal tract. ${ }^{11-13}$ Furthermore, the glycoproteins secreted by the goblet cells in the lower part of the crypt differ from those of the upper part. ${ }^{14}$ The question whether gut microbial flora or diet, or both in combination have an effect on the synthesis and secretion of intestinal mucins, or in the proportion of sulphated and sialomucins in the goblet cells of different regions of the gastrointestinal tract has not received sufficient attention.

It has been reported that diets containing fibre can modify the shape of villi ${ }^{15}$ in the small intestine of newly weaned rats and alter the cell turnover rates in the intestinal crypts. ${ }^{3}$ It is also well known that the turnover rate of epithelial cells is faster in conventional animals than in their germ free counterparts. In all species examined the villus:crypt ratio is higher in germ free animals, indicating that less proliferating tissue is required to keep the germ free mucosa intact. ${ }^{16}$

Our objective in this investigation was to evaluate whether the microbial flora, or diet, or both, affect the nature and distribution of the carbohydrates in the mucus secreting cells of a rat model and also to determine whether the intestinal morphology was altered by dietary modification. Two different types of diet were used. One was a commercial rodent diet composed of natural materials and the other was a nutritionally adequate mixture of purified ingredients. Because the composition of the indigenous gut microflora is characteristic of each species, the suitability of the conventional rat as a model for man is open to question. In an attempt to produce a model system more closely related to man several workers have used rodents born germ free and then associated with a flora of human origin (see review ${ }^{17}$ ). To obtain some preliminary evidence on possible species differences, our 
TABLE I Composition of diets fed to rats

\begin{tabular}{lc}
\hline Component & Concentration $(\mathrm{g} / \mathrm{kg})$ \\
\hline Purified diet: & \\
Casein & 250 \\
Maize starch & 380 \\
Potato starch & 100 \\
Sucrose & 50 \\
Cellulose powder & 80 \\
Soya bean oil & 60 \\
Mineral mix & 60 \\
Vitamin mix & 20 \\
Commercial diet & \\
Cereal products (barley, maize, & \\
wheat and wheatfeed) & 775 \\
Extracted soya bean meal & 107 \\
Fish meal & 98 \\
Mineral and vitamin supplement & 20 \\
\end{tabular}

* Calculated crude fibre content $4 \cdot 1 \%$.

study included one group of rats that harboured a flora of human origin. They received the purified diet; isolator space was inadequate to accommodate a similar group given the commercial diet. Their histochemical and morphological characteristics were compared with those of a corresponding group of germ free rats.

\section{Methods}

ANIMALS AND ASSOCIATION OF INTESTINAL MICROFLORA

Twenty five, 9 week old male rats were used for the study when they were killed. The germ free animals $(n=10)$ were born and maintained in plastic isolators while the conventional controls $(n=10)$ were kept in the open laboratory. Another five germ free rats were inoculated one week after weaning (that is, at 4 weeks of age) with a suspension of human faecal organisms by oral intubation (HFA) as described by Mallet et al. ${ }^{18}$ They were also maintained in an isolator.

DIETS

Five germ free and five conventional animals were fed on a commercial rat diet (diet GR3; Special Diets Service, Witham, Essex) (Table I). Five germ free rats and five conventional rats were maintained on a purified diet (Table I). The five HFA rats also received this diet.

PREPARATION OF TISSUES AND HISTOCHEMICAL METHODS

Animals were killed at 9 weeks of age and samples from the mid-region of the small intestine (jejunum) and proximal large intestine ( $2 \mathrm{~cm}$ from caecum) were fixed in $10 \%$ buffered formalin and embedded in paraffin wax.

Serial $5 \mu \mathrm{m}$ sections were subjected to the following procedures for the identification of mucosubstances:

(1) The periodic acid Schiff (PAS) reaction for studying unsubstituted $\alpha$-glycol rich neutral mucins.

(2) $1 \%$ Alcian blue, $\mathrm{pH} 2.5$ followed by PAS (AB 2.5/PAS) top allow neutral (pink) and acidic (blue) mucins to be differentiated. ${ }^{19}$ With this procedure a purple colour is obtained when neutral mucins are also present, and deep purple when neutral mucins are mainly present. ${ }^{20}$

(3) $1 \%$ Alcian blue, $\mathrm{pH} 1.0(\mathrm{AB} 1.0$ ) for the selective characterisation of sulphomucins. ${ }^{21}$ The Alcian blue dyes and the techniques used in this study were pretested in a dot blot assay for their suitability to label carboxylated and sulphated mucins, respectively. ${ }^{22}$ Semiquantitative staining intensities were based on a scale ranging from 0 , unreactive to +++ , intensely stained.

\section{QUANTITATIVE MORPHOLOGY}

Ten longitudinally oriented villi and crypts from the small intestine and 10 crypts from the large intestine were selected randomly from each animal for measurement. Villus length was measured from the tip to the base of villus and the crypt length was measured from the bottom of the crypt to the opening of the crypt. The results were expressed as mean (SEM), and statistical differences between groups were analysed for significance by Student's $t$ test.

\section{Results}

HISTOCHEMICAL STUDIES

The histochemical staining pattern of carbohydrate-containing surface mucus, surface goblet cells, and upper and lower crypt goblet cells is summarised in Tables II and III.

\section{Effects of diet}

The effects of diet were assessed by comparing the staining characteristics of germ free and

TABLE II Effects of diet and human flora on histochemical characteristics of intestinal mucins in germ free rats

\begin{tabular}{|c|c|c|c|c|c|c|c|c|c|}
\hline \multirow[b]{2}{*}{ Intestine and cell type } & \multicolumn{3}{|c|}{ Germ free fed conventional diet } & \multicolumn{3}{|c|}{ Germ free fed purified diet } & \multicolumn{3}{|c|}{ HFA inoculated fed purified diet } \\
\hline & $P A S$ & $A B 2 \cdot 5 / P A S$ & $A B 1 \cdot 0$ & $P A S$ & $A B 2 \cdot 5 / P A S$ & $A B 1 \cdot 0$ & $P A S$ & $A B 2 \cdot 5 / P A S$ & $A B 1 \cdot 0$ \\
\hline \multicolumn{10}{|l|}{ Small intestine: } \\
\hline Surface mucus & + & + purple & $(+)$ & ++ & + pink $++\mathrm{DP}$ & $(+)$ & ++ & + pink+DP & 0 \\
\hline Surface goblet cells & ++ & $+++\mathrm{DP}$ & + & ++ & +DP & ++ & ++ & ++DP & ++ \\
\hline Upper crypt goblet cells & +++ & $+++\mathrm{DP}$ & ++ & ++ & ++ purple & ++ & +++ & + purple & +++ \\
\hline Lower crypt goblet cells & + & $++\mathrm{DP}$ & 0 & ++ & $++\mathrm{DP}$ & + & $(+)$ & $+++\mathrm{DP}$ & $(+)$ \\
\hline \multicolumn{10}{|l|}{ Large intestine: } \\
\hline Surface mucus & $(+)$ & +purple & $(+)$ & + & ++ purple & $(+)$ & $(+)$ & +purple & ++ \\
\hline Surface goblet cells & + & ++ pink & 0 & ++ & $\begin{array}{l}+ \text { pink } \\
++ \text { purple }\end{array}$ & $(+)$ & ++ & + + pink & + \\
\hline $\begin{array}{l}\text { Upper crypt goblet cells } \\
\text { Lower crypt goblet cells }\end{array}$ & $\begin{array}{l}+ \\
++\end{array}$ & $\begin{array}{l}+ \text { pink } \\
++ \text { blue }\end{array}$ & $\begin{array}{l}+++ \\
(+)\end{array}$ & $\begin{array}{l}++ \\
+\end{array}$ & $\begin{array}{l}++ \text { DP } \\
+++ \text { blue }\end{array}$ & $\begin{array}{l}++ \\
(+)\end{array}$ & $\begin{array}{l}++ \\
(+)\end{array}$ & $\begin{array}{l}+\mathrm{DP} \\
+++ \text { blue }\end{array}$ & $\begin{array}{l}+++ \\
(+)\end{array}$ \\
\hline
\end{tabular}

Intensity of reaction: 0 no reactivity; $(+)$ weak reactivity: + moderate reactivity; ++ strong reactivity; +++ intense reactivity. $\mathrm{DP}=$ deep purple. $\mathrm{PAS}=$ periodic acid Schiff; $\mathbf{A B}=$ Alcian blue. 
TABLE III Effects of intestinal microflora on histochemical characteristics of intestinal mucins in conventional rats

\begin{tabular}{|c|c|c|c|c|c|c|}
\hline \multirow[b]{2}{*}{ Intestine and cell type } & \multicolumn{3}{|c|}{ Conventional rats fed commercial diet } & \multicolumn{3}{|c|}{ Conventional rats fed purified diet } \\
\hline & $P A S$ & $A B 2 \cdot 5 / P A S$ & $A B 1 \cdot 0$ & $P A S$ & $A B 2 \cdot 5 / P A S$ & $A B 1 \cdot 0$ \\
\hline \multicolumn{7}{|l|}{ Small intestine: } \\
\hline Surface mucus & ++ & + purple & 0 & $(+)$ & $\begin{array}{l}+ \text { pink } \\
++ \text { purple }\end{array}$ & 0 \\
\hline Surface goblet cells & +++ & $++\mathrm{DP}$ & $(+)$ & ++ & $++\mathrm{DP}+$ purple & ++ \\
\hline Upper crypt goblet cells & ++ & + purple & ++ & ++ & $\begin{array}{l}+ \text { pink } \\
++ \text { purple }\end{array}$ & + \\
\hline Lower crypt goblet cells & ++ & $++\mathrm{DP}$ & $(+)$ & + & $\begin{array}{l}+ \text { purple } \\
++ \text { DP }\end{array}$ & $(+)$ \\
\hline \multicolumn{7}{|l|}{ Large intestine: } \\
\hline Surface mucus & + & + purple & $(+)$ & 0 & + purple & 0 \\
\hline Surface goblet cells & +++ & $\begin{array}{l}+ \text { pink } \\
+ \text { purple }\end{array}$ & $(+)$ & + & $\begin{array}{l}++ \text { purple } \\
+ \text { pink }\end{array}$ & ++ \\
\hline Upper crypt goblet cells & +++ & $++\mathrm{DP}$ & ++ & ++ & $\begin{array}{l}++ \text { purple } \\
++ \text { pink }\end{array}$ & ++ \\
\hline Lower crypt goblet cells & ++ & ++ blue & + & $(+)$ & $\begin{array}{l}++ \text { blue } \\
+ \text { purple }\end{array}$ & $(+)$ \\
\hline
\end{tabular}

Intensity of reaction: 0 no reactivity; $(+)$ weak reactivity; + moderate reactivity; ++ strong reactivity; +++ intense reactivity. $\mathrm{DP}=$ deep purple. $\mathrm{PAS}=$ periodic acid $S$ chiff; $\mathrm{AB}=$ Alcian blue .

conventional rats receiving either the commercial or the purified diet.

Surface mucus. The PAS reaction of the surface mucus of the epithelium lining both the small and large intestines was more intense in the germ free rats fed on the purified diet. With $\mathrm{AB} 2 \cdot 5 / \mathrm{PAS}$ procedure in the germ free rats fed on the purified diet there was no purple staining in the surface mucus of the small intestine. In contrast, in conventional animals the pink and purple staining of surface mucus in the small intestine of rats fed on a purified diet indicates the presence of both neutral and acidic mucins.

Goblet cells. In germ free rats fed the purified diet, overall staining intensity was higher in the surface goblet cells and in the upper crypt goblet cells of the large intestine than in their counterparts fed on the commercial diet. In contrast to germ free rats, the goblet cells in the small and large intestine of conventional rats fed the commercial diet were found to be strongly PAS positive indicating abundant presence of neutral mucins.

The combined AB 2.5/PAS procedure showed appreciable differences between the relative proportions of acidic and neutral mucins in the goblet cells of rats fed on different diets. The surface and crypt goblet cells in the small intestine of the germ free rats fed the commercial diet stained deep purple

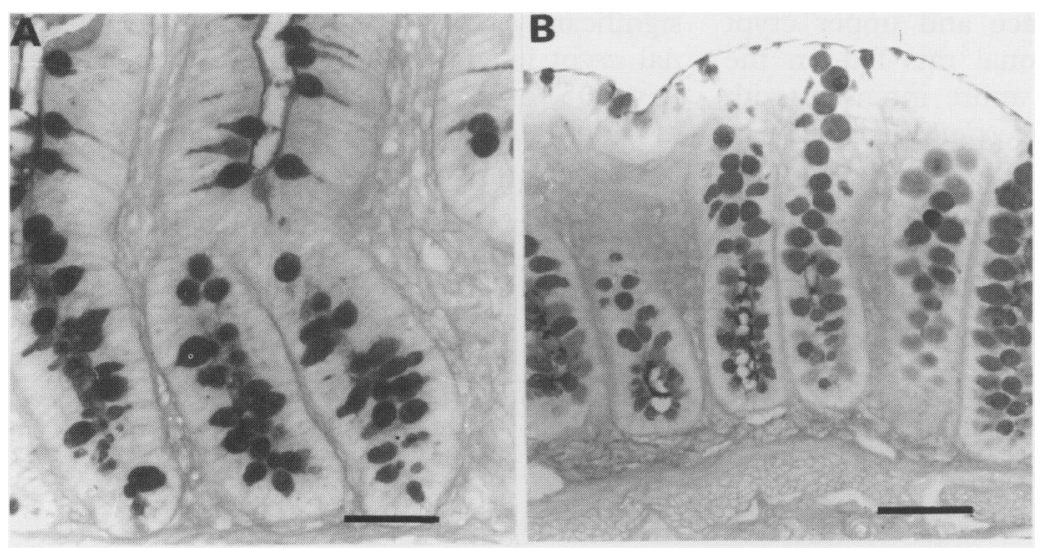

Figure 1: Mucosal epithelium of $(A)$ small intestine and $(B)$ large intestinal crypts from germ free rats fed on a commercial diet stained by Alcian blue-periodic acid Schiff technique. Surface goblet cells and crypt goblet cells in the small intestine are stained deep purple indicating that they contain both neutral and acidic mucins. Those in the large intestine are predominantly stained pink. (Bar=50 $\mathrm{mm}$ )
(Fig 1(A)), an indication that the neutral mucins predominant in these animals. The staining was less intense in the upper crypt goblet cells of the germ free rats fed purified diet. The surface goblet cells and upper crypt goblet cells in the large intestine of the germ free rats fed commercial diet contained no acidic mucins (Fig 1(B)), but they were present in the lower crypt goblet cells. In contrast, the staining reactions in the upper crypt goblet cells of the rats fed on the purified diet indicated the presence of acidic mucins, and the more intensely blue reaction in the deep crypt goblet cells of the large intestine of the germ free rats fed the purified diet indicates abundant presence of both sulphated and carboxylated acidic mucins. With the combined AB-PAS procedure, the surface goblet cells and upper crypt goblet cells of both the small and large intestine of conventional rats fed on a purified diet stained purple, an indication that the acidic mucins predominate in these animals. In the crypt goblet cells of conventional rats fed a commercial diet, the neutral mucins were found only in conjunction with the acidic ones but the pink reaction in some upper crypt goblet cells of the small and large intestine of conventional, purified diet fed rats indicates the presence of neutral mucins (Fig 2(A)).

$\mathrm{AB}$ staining at $\mathrm{pH} 1.0$ for assessment of sulphated mucins showed a higher sulphate content in the goblet cells of the small intestine of germ free rats fed a purified diet compared with those of conventional diet fed counterparts. In the large intestine the staining intensity was greater in the upper crypt goblet cells of germ free, commercial diet rats. The surface goblet cells of conventional rats fed on the purified diet stained more intensely with $\mathrm{AB} 1.0$ than those of their commercial diet fed counterparts (Fig 2(B)). Goblet cells at the bases of the crypts contained little or no sulphated mucins.

\section{Effects of the microflora}

To assess the effects of conventional microflora and of the interactions of the luminal nutrients with the conventional microflora on intestinal mucins, histochemical staining intensities were 


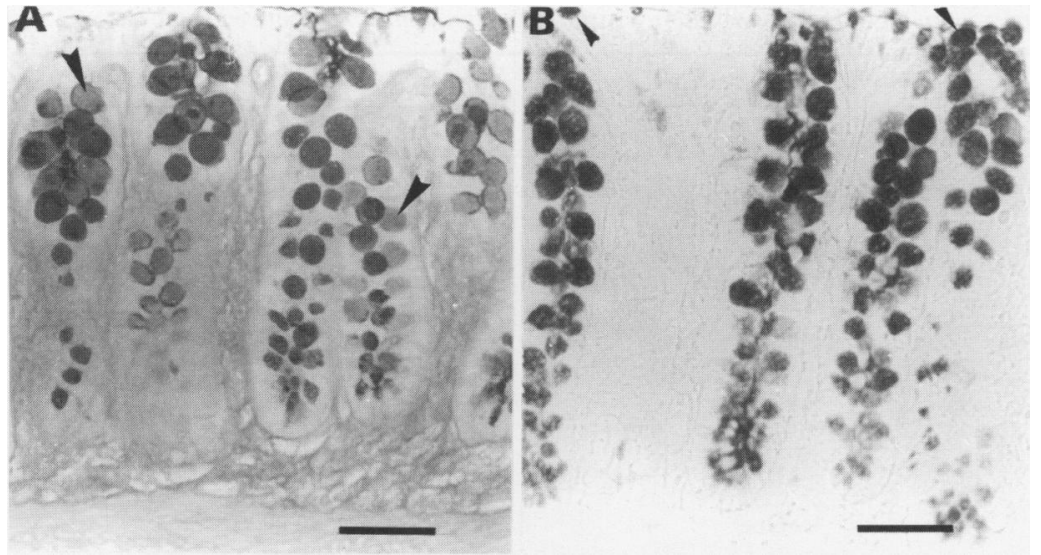

Figure 2: Large intestinal crypts of conventional rats fed on a purified diet stained with Alcian blue-periodic acid Schiff procedure and with Alcian blue at pH 1.0. (A) Goblet cells in the upper crypt containing neutral mucins and (B) surface goblet cells containing sulphated mucins are arrowed. (Bar $=50 \mu \mathrm{m})$ compared between germ free and conventional rats receiving the commercial diet and between germ free and conventional rats receiving the purified diet. The effects of human flora were assessed by comparing germ free and HFA rats receiving the purified diet.

Surface mucus. The PAS reactivity of the surface mucus of the epithelium lining both small and large intestines was more intense in conventional, commercial diet fed animals than in their germ free counterparts. However, the staining reaction in conventional rats fed on the purified diet was less intense than their corresponding germ free counterparts. The intensity of PAS reaction of the surface mucus was more intense in germ free, purified diet animals than in HFA, purified diet rats. No significant differences in the staining intensity of acidic mucins were detected between germ free and conventional commercial diet groups and between germ free and HFA purified diet groups with the combined AB-PAS procedure. However, in rats fed on a purified diet the surface mucus of conventional rats contained less neutral mucins than those of the corresponding germ free rats.

The surface mucus of HFA animals stained more intensely with PAS than in conventional, purified diet fed rats. In HFA rats the surface mucus of the large intestine contained more sulphate than that of conventional rats.

Goblet cells. The surface and upper crypt goblet cells of conventional rats fed on the commercial diet stained more intensely with PAS than those of the corresponding germ free rats. In contrast, overall PAS staining intensity of goblet cells was less intense in conventional animals fed on the purified diet than in their germ free counterparts. There was no regionally consistent difference between germ free and HFA rats fed purified diet; for instance, in the upper crypt cells the intensity was greater in the small intestine but less in the large intestine. PAS staining intensity was higher in the crypt goblet cells of the large intestine in germ free rats.

With the AB-PAS procedure no significant differences were seen between the conventional and germ free rats fed commercial diet and between germ free and HFA rats fed purified diet. However, in rats fed on a purified diet the purple staining reaction in goblet cells of both small and large intestine of conventional rats indicated the presence of acidic mucins, and the more intensely blue reaction in the lower crypt goblet cells of HFA rats indicates the presence of both sulphated and carboxylic acidic mucins.

Examination after $\mathrm{AB}$ staining at $\mathrm{pH} 1.0$ showed that goblet cells on the surface and in the upper and lower crypts of the small and large intestines of HFA, purified diet rats contained more sulphate than those of the corresponding germ free rats.

In rats associated with a human flora, overall PAS reactivity was higher in the goblet cells than in animals harbouring a conventional rat flora. With the AB-PAS procedure the upper crypt and surface goblet cells in the small and large intestine of conventional animals showed abundant presence of acidic mucins. In HFA rats, however, the acidic mucins were predominant in the deep crypt goblet cells of the large intestine. $\mathrm{AB}$ staining at $\mathrm{pH} 1.0$ detected more sulphate in the upper goblet cells of both the small and large intestines of HFA rats than those of the conventional rats.

\section{QUANTITATIVE MORPHOLOGY}

The quantitative data on the length of villi and crypts and villus:crypt ratio of the small intestines and length of crypts of the large intestines are summarised in Table IV. The germ free rats fed on a purified diet compared with those fed on a commercial diet had significantly reduced $(p<0.002)$ small intestinal crypt lengths but increased crypt lengths $(p<0.05)$ of the large intestine. No differences in villus lengths were observed between the

TABLE IV Effects of diet and intestinal microflora on rat intestinal morphology (values, mean (SEM))

\begin{tabular}{|c|c|c|c|c|c|}
\hline & \multicolumn{2}{|l|}{ Commercial diet } & \multicolumn{3}{|l|}{ Purified diet } \\
\hline & $\begin{array}{l}\text { Germ free } \\
\text { rats }\end{array}$ & $\begin{array}{l}\text { Conventional } \\
\text { flora rats }\end{array}$ & $\begin{array}{l}\text { Germ free } \\
\text { rats }\end{array}$ & $\begin{array}{l}\text { Conventional } \\
\text { flora rats }\end{array}$ & $\begin{array}{l}\text { Human flora } \\
\text { rats }\end{array}$ \\
\hline \multicolumn{6}{|l|}{ Small intestine: } \\
\hline Villus length $(\mu \mathrm{m})$ & $562.56(29 \cdot 2)$ & $604 \cdot 64(23 \cdot 1)^{\star}$ & $504 \cdot 60(65 \cdot 7)$ & $468.48(8) \ddagger$ & $396.96(50 \cdot 1)$ \\
\hline Crypt length $(\mu \mathrm{m})$ & $182.00(9 \cdot 1)$ & $180 \cdot 56(11 \cdot 7)^{\star}$ & $148 \cdot 10(5 \cdot 8) \dagger$ & $150 \cdot 72(3.5) \ddagger$ & $96.92(12.4)$ \\
\hline Villus:crypt ratio & $3 \cdot 12(0 \cdot 2)$ & $3.40(0 \cdot 2)$ & $3.37(0.3)$ & $3 \cdot 14(0 \cdot 1)$ & $4 \cdot 12(0 \cdot 2)$ \\
\hline $\begin{array}{l}\text { Large intestine: } \\
\text { Crypt length }(\mu \mathrm{m})\end{array}$ & $195 \cdot 52(6 \cdot 6)$ & $187.73(11 \cdot 8)^{\star}$ & $238 \cdot 5(12 \cdot 8) \dagger$ & $244 \cdot 4(8 \cdot 4) \ddagger$ & $152.08(21 \cdot 3)$ \\
\hline
\end{tabular}

For feeding regimes and experimental groups see table I and methods.

*Significantly different at $p<0.001$ from corresponding value for conventional rats fed a purified diet.

†Significantly different at $p<0.01$ from corresponding value for rats inoculated with human faecal flora.

ISignificantly different at $p<0.001$ from corresponding value for rats inoculated with human faecal flora.

Significantly different at $\mathbf{p}<0.01$ from corresponding value for rats inoculated with human faecal flora. 
two dietary groups. In rats harbouring a conventional microflora, the mean values of villus and crypt lengths of small intestine were significantly higher in the group fed on the commercial diet but there was a reduction in the crypt length in the large intestine.

The mean values of villus and crypt lengths of small intestine and crypt lengths of large intestine were similar in germ free and conventional rats fed commercial diet and in germ free and conventional rats fed the purified diet. There was no difference in the ratio of the villus length to crypt length in the small intestine. In rats fed on the purified diet association with the human flora resulted in a reduction in the villus and crypt length in the small intestine and of crypt length in the large intestine.

The rats associated with human flora when compared with those harbouring a conventional flora had significantly reduced lengths of small intestinal villi and reduced lengths of both small and large intestinal crypts.

\section{Discussion}

The present studies have confirmed the previous histochemical observations 81423 that the composition of secretory glycoproteins in the intestinal mucosa of rats differs with the region and with cell type. Our results in Tables II and III indicate that these differences in mucin composition are also influenced by diet and the presence or absence of a microbial flora in the intestinal lumen.

Neutral mucosubstances are the predominant type seen in the small intestine, whereas acid mucosubstances were predominant in the large intestine of conventionally reared animals. Furthermore, the goblet cells in the upper part of the large intestinal crypts differed from those in the lower part in that they contained $\mathrm{AB} \mathrm{pH} \quad 1.0$ reactive sulphated mucins. Although similar findings have been described in previous histochemical investigations, 89132425 the significance of the differences in mucin distribution patterns throughout the intestinal tract and functions of various classes of intestinal mucins is still not well understood.

The influence of diet on the composition of intestinal mucins was explored in germ free and conventional rats given either a diet of finely powdered purified ingredients, including cellulose as a source of fibre, or a more coarsely ground diet of natural ingredients containing crude fibre of mainly cereal origin. Our findings indicated generally less neutral mucins in the small intestine and the presence of sulphated mucins in both small and large intestines of animals fed on the purified diet, which might be accounted for by the different characteristics of the two diets, or of their fibrous components. Although histochemical studies on responses to dietary fibres have so far been limited to jejunal goblet cells of pigs, ${ }^{26}$ there are other morphological studies which report that specific dietary fibres may increase the secretory activity of goblet cells in rodents. ${ }^{327}$

The comparisons between germ free rats and their counterparts harbouring their indigenous flora showed that, independently of diet the intestinal tract responded to intraluminal contamination by depletion of neutral mucins from the globlet cells of the lower crypts of the small and large intestines. From the reactions observed to $A B$ staining, it is obvious that the presence of a microflora influences the relative proportions of sulphated and sialylated species of acidic mucins.

When the intensity of PAS reaction of germ free rats was compared with that in conventional rats, the surface mucus and goblet cells in rats harbouring a conventional flora were more intensely stained. It is well known that the amount of mucus in the intestinal lumen of germ free rats is greater than that in their conventional counterparts, because of the degradative effect of bacterial mucinase. However, as the parameter of staining intensity was analysed in this study, a direct analogy between staining activity and the amount of mucus cannot be drawn. The degree of glycosylation of mucus glycoproteins and hydration of secreted mucus may alter the staining intensity and it is possible that changes in the hydration of mucus may have been partly responsible for different staining intensities in our animals.

Changes in the carbohydrate composition of intestinal mucins have been known to occur during development ${ }^{28} 29$ and during the migration of crypt cells toward the epithelial surface. ${ }^{9}$ It is well known that the migration of epithelial cells along the villi is faster in conventional than germ free animals. In this study, in the presence of a conventional flora, goblet cell mucins in the large intestine became more sulphated along the crypt villus axis. This is consistent with studies in the neonatal mouse, where similar effects of the conventional flora on the production of mucins have been described. ${ }^{30}$ According to Heneghan ${ }^{16}$ the villus:crypt ratio is higher in germ free animals than conventional animals. This is in contrast with our findings which indicate comparable lengths of villus column and crypts in germ free animals and conventional animals fed on either the purified or the commercial diet. Similar results to ours have been observed in studies by Ishikawa $e \mathrm{al}^{31}$ in the upper region of the small intestine. When the morphological effects of the two diets were compared in our germ free animals, the most noticeable changes were seen in the crypt lengths of small and large intestines. Crypt size was decreased in the small intestine of rats fed a purified diet, and although the villus height did not change significantly, it was clear that the increased crypt length in the large intestine observed in this group of animals reflected an increased amount of neutral mucins. Our finding of no changes in villus lengths contrasts with the results of a morphological study on conventionally fed rats by Sigleo et $a l^{32}$ and this discrepancy suggests that there may have been an interaction between the diet and microbial activity ${ }^{33}$ in their studies.

Although the mechanisms responsible for structural and chemical changes in the intestinal mucosa are unknown, our results show that the presence of a microbial flora and the 
nature of the diet can determine the shape and mucus secretion of the intestinal epithelium and its supporting stroma. Since the thickness of the surface mucus and the chemical composition of surface mucins is linked to a dynamic equilibrium between the continuous secretion of mucins from the goblet cells and their degradation within the intestinal lumen, it is appropriate, therefore, to assess the composition of the surface mucus in response to intraluminal stimuli of different diets and different species of gut flora. The evaluation of surface mucus is prone to artifacts of fixation and should be considered with caution. It seems reasonable, however, to assume that the comparison between staining intensities of surface mucus in our animal groups, if all samples are processed at the same time and analysed by standardised histological methods, are valid. The effects of the human flora on the gut structure and mucus composition were in many ways similar to those of the indigenous rat flora. There were, however, some differences, for instance in the composition of the surface and goblet cell mucus and the length of the large intestinal crypt cells, which merit more detailed investigation. Although they may reflect real differences in response to the two types of flora, it is also possible that when a human flora is inoculated in the germ free animal, its establishment and subsequent interaction with the intestinal tract may induce changes not seen with an indigenous flora where colonisation is not subject to experimental manipulation.

The findings of altered mucosal morphology and mucin biosynthesis with particular dietary patterns in the presence of an indigenous or a human microbial flora described in this work strongly emphasises the use of the rat as a model system for pathogenesis of intestinal disease. Our results on human flora rats are preliminary and more detailed studies are needed to ascertain whether the HFA rat is a more appropriate model for man than the conventional rat. Further studies of changes in mucin composition by various intraluminal stimuli will help in understanding the mechanisms of intestinal disorders and in developing probes for detection of bowel disease. Morphometric analysis of goblet cell glycoproteins using an image processor is now being carried out in our animal model to further elucidate the interaction between the mucin secretion and intestinal luminal components.

The authors are grateful to the EC-FLAIR Concerted Action Programme No 9 which sponsored part of this work and to Dr Yoshio Saito, Calpis International Flora Laboratory, Kanagawa, Japan, for providing the purified diet.

1 Silberberg A, Meyer FA. Structure and function of mucus. Mucus in health and disease. II. Adv Exp Med Biol 1982;

2 Forstner JF. Intestinal mucins in health and disease. Digestion 1978; 17: 234-63.

3 Vahouny GV, Le T, Ifrim I, Satchithanandam S, Cassidy MM. Stimulation of intestinal cytokinetics and mucin
turnover in rats fed wheat bran and cellulose. Am $\mathcal{F}$ Clin turnover in rats fed wheat

4 Rozee KR, Cooper D, Lam K, Costerton JW. Microbial flora of the mouse ileum mucous layer and epithelial surface. Appl Environ Microbiol 1982; 43: 1451-63.

5 Ravdin JI, John JE, Johnston LI, Innes DJ, Guerrant RL.
Adherence of Entamoeba histolytica trophozoites to rat and human colonic mucosa. Infect Immun 1985; 48: 292-97.

6 Varcellotti JR, Salyers AA, Bullard WS, Wilkins TD. Breakdown of mucin and plant polysaccharides in the human colon. Can $\mathcal{F}$ Biochem 1977; 55: 1190-6.

7 Hoskins LC, Agustines M, McKee WB, Boulding ET, Kriaris M, Niedermeyer G. Mucin degradation in human colon ecosystems. Isolation and properties of fecal strains colon ecosystems. Isolation and properties of fecal strains
that degrade ABH blood group antigens and oligosacchathat degrade ABH blood group antigens and oligosaccha-
rides from mucin glycoproteins. $\mathcal{F}$ Clin Invest 1985; 75: 944-53.

8 Sheahan DG, Jervis HR. Comparative histochemistry of gastrointestinal mucosubstances. Am f Anat 1976; 146: 103-32.

9 Park CM, Reid PE, Owen DA, Volz D, Dunn WL. Histochemical studies of epithelial cell glycoproteins in normal rat colon. Histochem f $1987 ; 19: 546-54$.

10 Filipe MI, Fenger C. Histochemical characteristics of mucins in the small intestine. A comparative study of normal mucosa, benign epithelial tumors and carcinoma. Histochem $₹$ 1979; 11: 277-87.

11 Spicer SS. A correlative study of the histochemical properties of rodent acid mucopolysachharides. $\mathcal{f}$ Histochem Cytochem 1960; 9: 18-33.

12 Spicer SS. Diamine methods for differentiating mucosubstances histochemically. $\mathcal{F}$ Histochem Cytochem 1965; 13: 211-34

13 Tsuyama S, Suzuki S, Murata F. The histochemical differences of intestinal gland epithelia in the rat colon with special reference to their glycoconjugates. Acta Histochem Cytochem 1983; 16: 456-71.

14 Altmann GG. Morphological observations on mucussecreting non goblet cells in the deep crypts of the rat ascending colon. Am $\mathcal{f}$ Anat 1983; 167: the rat

15 Tasman-Jones C, Owen RL, Jones AL. Semipurified dietary fibre and small bowel morphology in rats. Dig Dis Sci 1982; 27: 519-24

16 Heneghan JB. Physiology of the alimentary tract. In: Coates $\mathrm{ME}, \mathrm{Gustafsson} \mathrm{BE}$, eds. The germ-free animal in biomedical research. London: Laboratory Animals Ltd, 1984 169-91.

17 Rumney CJ, Rowland IR. In vivo and In vitro models of the human colonic flora. Crit Rev Food Sci Nutr 1992; 31: 299-331.

18 Mallett AK, Bearne CA, Rowland IR, Farthing MJG, Cole $C B$, Fuller $R$. The use of rats associated with a human fecal flora as a model for studying the effects of diet on the human gut microflora. F Appl Bacteriol 1987; 63: the humar 45 .

19 Mowry RW. The special value of methods that colour both acidic and vicinyl hydroxyl groups in the histochemical study of mucins, with revised directions for the colloidal iron stain, the use of alcian blue $8 \mathrm{Gx}$ and their combination with the periodic acid Schiff reaction. Ann NY Acad Sci 1963; 106: 402-23.

20 Filipe MI. Mucins in the human gastrointestinal epithelium: A review. Investigative Cell Pathology 1979; 2: 195-216.

21 Lev R, Spicer SS. Specific staining of sulphate groups with alcian blue at low pH. $\mathcal{F}$ Histochem Cytochem 1964; 12: 309.

22 Schumacher U, Adam E. A dot blot technique of standardisation of staining in glycosaminoglycan histochemistry: alcian blue, its analogues, and diamine methods. Biotechnic and Histochemistry 1994; 69: 18-24.

23 Reid PE, Culling CFA, Dunn WL. The histochemical interpretation of the complex results of methylation upon gastrointestinal tract mucins with special reference to the periodic acid-Schiff reactivity. $\mathcal{F}$ Histochem Cytochem 1974; 22: $986-91$

24 Shamsuddin AKM, Trump BF. Colon epithelium I. Ligh microscopic, histochemical and ultrastructural features of normal colon epithelium of male Fischer 344 rats. $\mathcal{f}$ Nat Cancer Inst 1981; 66: 375-88.

25 Thomopoulos GN, Schulte BA, Spicer SS. Light and electron cytochemistry of glycoconjugates in the rectosigmoid colonic epithelium of the mouse and rat. Am $\mathcal{F}$ Anat 1983 ; 168: 239-56.

26 Moré J, Fioramonti J, Bénazet F, Buéno L. Histochemical characterization of glycoproteins present in jejunal and colonic goblet cells of pigs on different diets. Histochemistry 1987; 87: 189-94.

27 Cassidy MM, Lightfoot FG, Vahouny GV. Morphological aspects of dietary fibre in the intestine. Adv Lipid Res 1982; 19: 203-28.

28 Brackett KA, Townsend SF. Organogenesis of the colon in rats. $\mathcal{F}$ Morphol 1980; 163: 191-201.

29 Sharma R, Schumacher U. Histochemical characterization of carbohydrate residues during the morphogenesis of gastrointestinal and respiratory systems of Caretta caretta. Acta Histochem 1992; 93: 41 1-32.

$30 \mathrm{Hill}$ RRH, Cowley HM, Andremont A. Influence of colonizing micro-flora on the mucin histochemistry of the neonatal mouse colon. Histochem $\mathcal{f}$ 1990; 22: 102-5.

31 Ishikawa K, Satoh Y, Tanaka H, Ono K. Influence of conventionalization on small-intestinal mucosa of conventionalization on small-intestinal mucosa of
germ-free wistar rats: Quantitative light microscopic germ-free wistar rats: Quantitative light
observations. Acta Anat 1986; 127: 296-302.

32 Sigleo S, Jackson MJ, Vahouny GV. Effects of dietary fibre constituents on intestinal morphology and nutrient transport. Am f Physiol 1984; 246: G34-9.

33 Savage DC. Factors involved in colonization of the gut epithelial surface. Am $\mathcal{F}$ Clin Nutr 1978; 31: S131-5. 